\title{
The Expenditure Benchmark: Complex and Unsuitable for Independent Fiscal Institutions
}

\author{
Carlos Fonseca Marinheiro ${ }^{1,2}$ (D)
}

Accepted: 12 April 2021 / Published online: 28 June 2021

(c) Association for Comparative Economic Studies 2021

\begin{abstract}
The expenditure benchmark is an indicator for the evolution of public expenditure introduced in 2011 in the already complex European fiscal rules framework, being a very specific application of an expenditure rule. However, it is a quite complex indicator and not suitable for the use at national level by the Independent Fiscal Institutions - that monitor compliance with national fiscal rules - as it relies on the European Commission's data inputs and judgement not available in real time. This paper argues for more transparency and for a simplification of this indicator to reduce the reliance on non-observable variables. Such improvements are essential as most existing proposals to reform the European Union's fiscal rules aim to use an expenditure rule as the operational fiscal rule, a role the expenditure benchmark as is cannot fulfil.
\end{abstract}

Keywords Expenditure benchmark · Independent Fiscal Institutions · EU fiscal rules $\cdot$ Stability and Growth Pact

JEL Classifications E61 $\cdot$ E02 $\cdot$ E62 $\cdot$ H50 $\cdot$ H61

\section{Introduction}

The expenditure benchmark (EB) was introduced by the 2011 "Six-Pack" reform to the Stability and Growth Pact (SGP) legislation in Europe in response to the ongoing sovereign debt crisis. Its purpose was to overcome some of the shortcomings of the structural budget balance (SBB) calculation, which is an indicator based on a non-observable variable subject to frequent revisions. The EB was supposed to

Carlos Fonseca Marinheiro

carlos.marinheiro@cfp.pt

1 Portuguese Public Finance Council (Conselho das Finanças Públicas), Praça de Alvalade, 6, 10, 1700-036 Lisboa, Portugal

2 Faculty of Economics, University of Coimbra, Avenida Dias da Silva, 165, 3004-512 Coimbra, Portugal 
provide "more operational guidance to the Member States in the conduct of prudent fiscal policies, by focusing surveillance on indicators directly under the control of the government" (see the Communication from the European Commission COM (2020) 55 final, Box 1). The EB is a very specific implementation, in the context of the European Union (EU) framework for the supranational surveillance of the fiscal policies of Member States, of a more general fiscal rule that imposes a limit on aggregate expenditure of general government or subsets thereof. Over time the Commission has been making the case for a more prominent role for the EB in both the preventive and the corrective arm of the SGP. ${ }^{1}$ More recently, several proposals to reform the economic governance of the euro area aim to give to the EB or to a more general expenditure rule an even stronger role in the rules-based European fiscal framework.

The EB was added as an additional layer to the European fiscal rules framework, which comprised reference values for the general government deficit and gross public debt, a Medium Term Objective (MTO) for the structural budget balance (SBB), and a required adjustment path towards it. At the same time, it was also introduced a debt rule to operationalize the debt criteria of article 126 of the Treaty on the Functioning of the European Union (TFEU known also simply as the Treaty). This set of rules is not entirely consistent. ${ }^{2}$ As recognized by (European Commission 2020a), the fiscal framework "has grown excessively complex" and is "increasingly complex" (European Commission 2021). Darvas and Anderson (2020) go further and claim it suffers from "extreme complexity" while (Thygesen et al. 2020) refer to "an intractable set of rules and benchmarks". The layers over layers of complexity were even compared to the Cathedral of Seville (Blanchard et al. 2020) and to the Mosque-Cathedral of Cordoba by Gaspar (2020): complex constructions whose original structure is still recognizable, but where many successive additions leaves the consistency of the whole indecipherable. The complexity is the cost of pursuing multiple objectives (such as debt sustainability and economic short-term stabilization) with elements of flexibility and discretion (European Commission 2020a). Moreover, as this paper shows, the EB is per se a very complex indicator.

The paper concludes that the current design of the EB is not fit to serve all purposes it was created for. Overall, the EB as is: (1) is not an operational indicator directly under the control of the government; (2) still relies on non-observable

\footnotetext{
1 The Code of Conduct on the Stability and Growth Pact now includes the Opinion of the Economic and Financial Committee on "Improving the predictability and transparency of the SGP: A stronger focus on the expenditure benchmark in the preventive arm", and the Opinion of the Economic and Financial Committee on "Improving the assessment of effective action in the context of the excessive deficit procedure-A specification of the methodology", both endorsed by the Economic and Financial Affairs (ECOFIN) Council on 6 December 2016. The SGP has "two harms" corresponding to the Council Regulations (EC) 1467/97 and 1466/97, respectively: the corrective harm for countries under an Excessive Deficit Procedure (EDP) due to non-compliance with the deficit or the debt requirements of the Article 126 of the Treaty, and the preventive arm that aims to ensure sound budgetary policies to allow the full functioning of automatic fiscal stabilzers over the economic cycle while avoiding excessive government deficits.

2 This paper will call the reader's attention to inconsistencies between the SBB and EB reflecting the imperfect way as such rules and indicators where put together in the framework.
} 
variables and on data inputs that are not readily available; (3) is not fully consistent with the structural budget balance by design; (4) the Commission has almost full discretion regarding the classification of Discretionary Revenue Measures that are netted-out from its calculation; (5) is very complex to calculate and to replicate, and thus not suitable to monitoring by national Independent Fiscal Institutions (IFIs) in real-time, being also very difficult to communicate to the public.

This paper thus contributes to the current policy discussion on the usefulness of the EB for policy surveillance, making suggestions on how to improve its governance, simplifying the indicator and taking into account the creation of Independent Fiscal Institutions (IFIs) in the Member States, simultaneously improving its transparency and enforceability. This paper also adds to the literature on the Stability and Growth Pact (SGP) the identification of internal inconsistencies in the EU fiscal framework, namely between the SBB and the EB, as well as a detailed assessment of the EB mechanics. The paper also adds to the literature on the reform proposals to the EU fiscal framework. Most of them are in favour of keeping debt sustainability as the main policy objective, while making use of an operational indicator in full control of the national Governments, usually in the form of an expenditure rule [see for instance (Carnot 2014; Claeys et al. 2016; Beetsma 2017; Bénassy-Quéré et al. 2018; Kopits 2018; Darvas et al. 2018; European Fiscal Board 2019, 2020a; Hauptmeier and Kamps 2020; Thygesen et al. 2020; Darvas and Anderson 2020; European Commission 2020a; EU Independent Fiscal Institutions 2021)]. This paper complements such literature arguing that the EB in its current form is not fit to be such operational rule, while providing several reform options on both its setup and governance.

The rest of the paper is structured as follows. Section briefly reviews the role of an expenditure rule in the fiscal rules literature and in the EU fiscal framework. Section "The Concept of the Expenditure Benchmark" provides details on the calculation of the EB and how it relates with the SBB. Section "Continued Reliance on Non-observables" makes the point that the EB still relies on non-observable variables. Section "The IFIs' Role in the EB" examines the role of national IFIs in the EB. Section "Conclusions and Policy Recommendations" concludes the paper and makes some policy recommendations to improve the EB design and governance.

\section{Expenditure in the EU Rules-Based Fiscal Framework}

According to Kopits and Symansky (1998) seminal definition, a fiscal rule sets permanent constrains on fiscal policy, typically defined in terms of a summary indicator of fiscal performance often expressed as a numerical ceiling or target in proportion to GDP. Ideally, a fiscal rule should be well defined, transparent, adequate, consistent, simple, flexible, enforceable, and efficient according to the same authors. Yet, (Debrun and Jonung 2019) point to the impossibility of simultaneously achieving simplicity, flexibility, and enforceability leading to the emergence of a trilemma.

Firstly applied to subnational governments, a rules-based fiscal framework at the General Government level only became the norm when a group of EU countries committed to adopt a single currency by signing in 1992 the Maastricht Treaty 
(Debrun and Jonung 2019). ${ }^{3}$ Successive reforms added new elements in a sedimented framework (Deroose et al. 2018): the SGP was agreed in 1997, entering into force in 1999; it was first reformed in 2005 operationalizing the "medium term objective of budgetary positions of close to balance or in surplus" by the use of the SBB; in 2011 the SGP was again reformed by the so-called "Six-Pack" which added the EB and a debt rule, among other developments including the Directive 2011/85/ EU calling for a reinforcement of the national fiscal frameworks; in 2013 the "TwoPack" further strengthened the national fiscal frameworks requiring national IFIs to produce or endorse or the macroeconomic forecasts used for fiscal programing and to monitor compliance with national numerical fiscal rules. The 2012 intergovernmental Treaty on Stability, Coordination and Governance in the Economic and Monetary Union (TSCG), two codes of conduct and significant interpretational changes are also part of the framework. ${ }^{4}$

The increase indebtedness as a response to the current COVID-19 pandemic will pose a challenge to the rules-based framework (EU Independent Fiscal Institutions 2021; Thygesen et al. 2021). Blanchard et al. (2021) propose the abandonment of fiscal rules in favour of fiscal standards to be enforced by the Commission in a more discretionary way, with the European Court of Justice or an independent agency as an adjudicator. ${ }^{5}$ However, the required Treaty change makes it very difficult to be implemented (Constâncio 2020), and the proposed mechanism goes against the political will expressed in the Treaty that ruled out the legal route to enforce article $126 .{ }^{6}$ Thus, a well-designed rules-based framework along the features sought by Kopits and Symansky (1998) and Wyplosz (2013) both at the national and supranational level can help to achieve fiscal discipline and is worth preserving (Debrun and Jonung 2019; Barbier-Gauchard et al. 2021) to ensure counter-cyclical fiscal policy responses (Bergman and Hutchison 2015; Larch et al. 2021) and ultimately debt sustainability (European Commission 2020a). ${ }^{7}$ As mentioned before, most reform proposals aim at an expenditure rule as the single operational target, but this paper argues that the unreformed EB is not up to the task.

\footnotetext{
${ }^{3}$ Lledó et al. (2017) provide an overview of the national and supranational rules adopted by 96 countries, based on the IMF Fiscal Rules Dataset 1985-2015. On the institutional arrangements between the central and subnational governments in federations, including fiscal rules, and possible extrapolation to the EU see the contributions in Cottarelli and Guerguil (2015).

${ }^{4}$ European Commission (2019b) provides a 100 pages useful summary of the rules.

5 Also differently from the more conventional view, (Baret and Barbier-Gauchard 2021) propose simplify the SGP's preventive arm making use of machine learning in a risk management approach to foresee breaches of the deficit reference value.

6 Additionally, the proposal to give the Commission the power to delay the adoption of a national budget if a given Member State did not comply with a requested change goes against the powers of national Parliaments, being most likely unconstitutional in many Member States.

7 Using real-time data (Marinheiro 2008) found that discretionary fiscal policy in euro-area countries was designed to be procyclical in the period 1999-2006. (Larch et al. 2021) reach a similar conclusion for the EU and beyond, concluding this is first and foremost a matter of political economy, and that compliance with EU rules reduces the likelihood of running pro-cyclical policies. Fiscal rules can also have positive effects on fiscal discipline and fiscal credibility of developing countries (Tapsoba 2012).
} 
Introduced in the reform package of 2011, the EB was meant to complement the structural balance indicator overcoming its shortcomings. Under the former rule, EU Member States are required to reach a country-specific Medium-Term Objective (MTO) defined in terms of the structural balance. An annual fiscal adjustment towards the MTO is required and modulated taking into account the economic cycle, the debt level, and the sustainability needs according to a matrix of requirements incorporated into the Code of Conduct on the SGP. Back in 2011, the EB was devised as a complementary instrument for countries to reach or stay at their respective MTO: the relevant net expenditure should grow in line with the reference potential growth rate when at the MTO or grow by less than that rate if the country is not yet at the MTO. The assessment of compliance of the preventive arm of the SGP takes into account both the structural balance and the EB. ${ }^{8}$

The structural budget balance is a non-observable variable of the underlying budget balance that would be obtained if the economy were at its full production potential, which is at the core of the preventive arm of the SGP. It is an interesting theoretical concept that allows distinguishing the discretionary fiscal measures from the working of the automatic stabilizers, therefore assessing the fiscal stance. However, in practice, the calculation of the structural balance requires several (strong) assumptions to estimate the economic cycle and its impact on the budget balance. As a result, the structural balance estimates are frequently revised, which has led to an increasing criticism on its use for fiscal surveillance purposes (Darvas and Anderson 2020). Some of its critics advocate a fiscal rule that is simpler to calculate and operationalize, inter alia an expenditure rule (Andrle et al. 2015).

There are several advantages of a well-designed expenditure rule, as exposed by the IMF (2014) and (Bedogni and Meaney, 2017): it helps containing the expenditure growth to values consistent with a sustainable debt trajectory; it is countercyclical, "shielding" expenditure from cyclical revenue fluctuations; allows the anchoring of medium-term fiscal frameworks; and, are enforceable and predictable as an expenditure rule maps directly into the formulation of the annual budget. However, as is the case for any fiscal rule, to present such benign features several pre-conditions must be fulfilled in the form of adequate public finance management (Cangiano et al. 2013), adequate institutions (Strauch et al. 2009), proper design to counter-act some disadvantageous effects and, as stressed by the IMF (2014), "fundamental genuine commitment of policymakers to sound and high-quality public finances". 9

An expenditure rule has its disadvantages, including a political incentive to preserve some low-quality projects with short-term political dividends at the expense

\footnotetext{
${ }^{8}$ Article 5 of Council Regulation (EC) No. 1466/97 states that "Sufficient progress towards the mediumterm budgetary objective shall be evaluated on the basis of an overall assessment with the structural balance as the reference, including an analysis of expenditure net of discretionary revenue measures". The SGP Vade-Mecum (European Commission, 2019b, chap. 1.3.7) provides details of such overall assessment.

9 On the importance of the political commitment to the success of expenditure targets and how to reconciliate the EU fiscal framework with operational Medium-Term Budgetary Frameworks at the national level see EU Independent Fiscal Institutions (2018b).
} 
of higher-quality programs with long-term productive benefits - as is the case of productive public investment (Bedogni and Meaney 2017; Guerguil et al. 2017). ${ }^{10}$ Another limitation is that a spending rule by itself does not take into account the ability of the revenue system to withstand a (large) negative shock (Bedogni and Meaney 2017). So an expenditure rule could be complemented by other rules (Debrun et al. 2008; Cordes et al. 2015). ${ }^{11}$

The design of the expenditure rule matters as well. As will be shown, the EB does not present the characteristics of being simple, transparent, consistent and enforceable that an ideal fiscal rule should contain according to (Kopits and Symansky 1998). There is already some evidence of the EB's design and governance flaws: not a single significant deviation procedure was launched due to non-compliance with the EB, despite some euro area member states showed deviations from the required benchmark larger than the significance threshold, even after some ad hoc changes made in the calculation of the benchmark by the Commission in the recent years (see European Fiscal Board 2018, 2019). Still according to the European Fiscal Board (EFB), in the case of Latvia, Portugal, and Slovakia, although the overall assessment based on the structural balance and the expenditure benchmark pointed to a significant deviation in 2018 , the Commission concluded that there was "no sufficient ground to conclude on the existence of an observed significant deviation" by referring to a number of factors beyond the reading of the two numerical indicators, that is, the SBB and the EB (European Fiscal Board 2019, pp. 27-28). ${ }^{12}$ The overly complex design of the EB creates a formidable communication challenge that makes it politically more difficult to sanction a non-compliant member by their peers in ECOFIN. Therefore, in my view, complex design and governance flaws reinforce each other in a way that undermines enforceability.

\section{The Concept of the Expenditure Benchmark}

\section{The Calculation of the Benchmark}

The EB applies to a modified public expenditure aggregate that excludes interest expenditure, expenditure on EU programs fully matched by EU funds revenue, and

\footnotetext{
10 In a note of caution, Guerguil et al. (2017) found that while expenditure rules are counter-cyclical, they are also associated with procyclical changes in investment spending. Additionally, Sacchi and Salotti (2015) found that budget balance rules are more effective at leading discretionary fiscal policy to enhance macroeconomic stability than rules targeting different aggregates as expenditures, revenues, or debt. Yet, Cordes et al. (2015) found that expenditures rules were associated with a decrease in public investment only in emerging economies.

11 Bedogni and Meaney (2017) make the point that "a revenue rule, where greater than expected revenues could be set aside for either a contingency fund or for investment in capital projects, would adequately complement the expenditure rule and ensure there are savings to deal with future shocks".

12 In 2019, the noncompliance with EB requirements increased, and contrary to the previous years, the deviations were deemed significant (in the May 2020 assessment), but were inconsequent as no significant deviation procedure was opened on the account of the deep economic crisis triggered by the COVID-19 pandemic (European Fiscal Board 2020a; Thygesen et al. 2020).
} 
Box 1 Steps in the calculation of the net expenditure growth (nominal) adjusted from one-offs

For a determined year $t$ :

Step 1

Modified expenditure aggregate in $t\left(M G_{t}\right)=$ General Government Expenditure in $t$-Interest Payments in $t$-Government expenditure on EU programs fully matched by EU funds revenue in $t$ Nationally financed gross fixed capital formation in $t+$ Annual average of nationally financed gross fixed capital formation from $t-3$ to $t$-Cyclical unemployment expenditure in $t$-One-offs expenditure in $t$

Step 2

Calculation of the incremental impact for year $t$ of discretionary revenue measures having an incremental effect on revenues collected in $t$ with respect to $t-1$ adjusted for one-offs $\left(\Delta R_{t}\right)$. The adjustment for one-offs requires subtracting the annual change in revenue side one-offs

$\Delta R_{t}=\mathrm{DRM}_{t}+$ RML $_{t}-\Delta$ One-offs Revenue ${ }_{t}$

Step 3

Net expenditure growth rate $(\mathrm{mg})$ for year $t: \mathrm{mg}_{t}=\left(M G_{t}-\Delta R_{t}-M G_{t-1}\right) / M G_{t-1}-1$

Source Based on European Commission (2019b), Box 1.11.

the cyclical element of unemployment benefit expenditure. This directly follows the definition in the SGP Regulation. ${ }^{13}$ In addition, the nationally financed government investment is averaged over 4 years to smooth the impact of any large investment projects. Besides, when assessing compliance with the $\mathrm{EB}$, the impact of one-off measures is systematically corrected for. ${ }^{14}$ The government size among EU Member States is highly heterogeneous - ranging the expenditure-to-GDP ratios from $25 \%$ to $55 \%$ - so the EB could not constrain countries with a low expenditure ratio from increasing it, as long as such increase is financed by additional revenue (therefore not threatening sustainability). As a result, the modified expenditure aggregate is subtracted from discretionary revenue measures (DRM) and revenues mandated by law (RML) before it is compared with the reference rate, which leads to the "net modified expenditure aggregate", i.e. net of DRM. ${ }^{15}$ The DRM enter this calculation also net of the (annual) change in the use of one-offs on the revenue side of the budget. ${ }^{16}$ The steps for the calculation of the net expenditure growth (nominal) adjusted from one-offs are presented in Box 1.

The net expenditure growth rate is compared with the appropriate reference rate both in nominal and real terms. This is the medium-term growth rate of potential GDP, calculated as a 10-year average comprising 5 years of backward-looking data, the year underway and 4 years of forward-looking data (i.e., 4 years of forecasts).

\footnotetext{
13 According to the Council Regulation (EC) No. 1466/97, "The expenditure aggregate shall exclude interest expenditure, expenditure on Union programmes fully matched by Union funds revenue and nondiscretionary changes in unemployment benefit expenditure".

14 At the start of the application of the EB, there was no correction for one-offs, which was a source of conflict with the SBB analysis when there were sizable one-offs (see Bedogni and Meaney 2017) for the case of Ireland).

15 For the sake of simplicity, since the RML are not very common and are subject to the same treatment of DRM, the remaining of the text will not make an explicit reference to them.

16 This calculation uses the change and not the level of one-offs because the EB ultimate objective is to calculate a "corrected" variation rate of expenditure, and not a "corrected" expenditure level.
} 
For countries not yet at the MTO the net expenditure must grow less than the potential reference rate to ensure convergence to the MTO. This is achieved by subtracting a "recalibrated convergence margin" to the potential GDP growth. According to the (European Commission 2019b), "the convergence margin is calculated based on the assumption that any decrease in the share of public expenditure that is not financed by additional revenue measures (which would occur if net expenditure grows more slowly than GDP) would lead to an exactly proportional improvement in the structural balance (the coefficient being equal to the share of public expenditure in GDP times the shortfall of expenditure growth). Therefore, the size of the convergence margin depends on the size of the general government sector, with larger public sectors requiring less expenditure restraint in percentage terms to yield a particular tightening of the structural budget". The convergent margin can be quite large, increasing with the distance from the structural balance to the MTO and decreasing with the expenditure ratio. ${ }^{17}$

Both the potential GDP growth and the convergence margin for year $t$ are set based on the European Commission Spring forecast made in year $t-1$ and are kept "frozen" until its assessment in the Spring of year $t+1$. As both are defined in real terms and the expenditure is at current prices, the GDP deflator for year $t$ from the $t-1$ Spring Commission forecast is used.

To ensure consistency with the structural balance pillar of the preventive arm of the SGP the so-called flexibility clauses are also taken into account (meaning netted out): structural reforms, pension reform, investment clause, refugee and security, and "other unusual events".

\section{Conciliation with the Structural Balance Rule}

Some of the governance problems of the EB are due to the way as this new expenditure rule was added as an additional layer in the preventive arm of SGP that already comprised a structural balance rule. To ensure some consistency between such two indicators the EB calculation had to include elements of the SBB estimation, including non-observable components at the cost of increasing complexity. However, differences between the two indicators are unavoidable, leading to the need of an overall assessment to reach a conclusion regarding compliance with the SGP, which increases the scope for judgement in the assessment process.

Theoretically it is possible to derive a structural primary expenditure growth consistent with a given structural balance change. As demonstrated in Appendix, the growth rate of structural primary expenditure is given by:

\footnotetext{
17 The convergence margin for year $t$ is obtained dividing the required tightening (in the structural balance) in percentage points of GDP by the share of government primary expenditure in GDP in year $t-1$, using as source the values from the Spring forecast (published in $t-1$ ). For Member States at their MTO, the convergence margin is by construction set to zero. A negative value is not calculated for countries that have overachieved their MTO. The following section shows how the convergence margin should had been calculated in order to ensure consistency with the SBB.
} 


$$
\frac{d(\mathrm{PE})}{\mathrm{PE}}=g+\frac{d(\mathrm{SDEF} / Y)}{\mathrm{PE} / Y}+\frac{d(R / Y)-d(r B / Y)}{\mathrm{PE} / Y},
$$

where PE is the structural primary expenditure, $Y$ is the potential GDP and $g$ its growth rate, SDEF is the structural deficit, $R$ is structural revenue and $r$ is the implicit interest rate on public debt $(B)$.

The EB framework could be written as implying:

$$
m g_{t}=\bar{g}-\frac{-d\left(\mathrm{SDEF}_{t}^{\mathrm{req}} / Y_{t}\right)}{\mathrm{PE}_{t-1}^{\mathrm{obs}} / \mathrm{GDP}_{t-1}},
$$

since for the Member States not at their respective MTO the growth rate of the modified (primary) expenditure aggregate net of one-offs and DRM $\left(m g_{t}\right)$ should equal the reference medium-term potential growth $(\bar{g})$ less the convergence margin, which is calculated as the annual required improvement in the structural balance (i.e., the symmetric of the structural deficit) in percentage points of GDP-in this notation $-d\left(\mathrm{SDEF}_{t}^{\mathrm{req}} / Y_{t}\right)$-divided by the observed primary expenditure $\left(\mathrm{PE}^{\mathrm{obs}}\right)$ to GDP ratio in the previous year.

Confronting the two expressions above we can conclude that the EB framework could give rise to different results from the application of the structural balance (improvement) rule due to several factors, namely:

i. The reference medium-term rate for potential output growth $(\bar{g})$ used in the EB might differ from the current year potential output growth that would be consistent with the structural balance rule $\left(g_{t}\right)$. Such divergence was clearly visible in the post-sovereign debt crisis data because the reference rate was still influenced by lower potential growth during the crisis years while there was a rebound in current potential output growth.

ii. Revenue changes not induced by DRM or by the cyclical developments, as it is the case of the revenue windfalls or shortfalls that impact on the SBB.

iii. Significant changes in interest payments to GDP ratio, due to large swings in the implicit interest rate on debt, could originate a windfall (when there is a sharp decrease in the ratio of interest payments) or a shortfall, on the reverse case, in the calculation of the SBB.

iv. Specificities in the calculation of the modified expenditure aggregate for the EB framework: ${ }^{18}$

a. To be completely consistent with the structural balance rule the EB should be based on the structural primary expenditure, which according to the EU's commonly agreed methodology is obtained by subtracting the cyclical com-

\footnotetext{
18 The other adjustments in the calculation of the modified expenditure aggregate, such as the removal of expenditure financed by EU funds, are necessary to ensure consistency since such funds are neutral to the budget balance; the same applies to the adjustment for one-offs, which are also removed for the calculation of the structural balance.
} 
ponent of the expenditure to the primary expenditure ratio. ${ }^{19}$ However, the EB subtracts a cyclical unemployment expenditure that is calculated differently and could even show an opposite sign (see below).

b. Also to ensure consistency, the convergence margin for the EB should be calculated dividing the required adjustment by the ratio of structural primary expenditure to potential GDP, and not by the observed primary expenditure ratio to GDP.

c. The EB considers an average of domestically financed investment while for the structural balance it is the total current investment that matters.

\section{Continued Reliance on Non-observables}

Due to the original conception of the EB as a complementary tool to the structural balance pillar and the need to ensure consistency between the two pillars of the SGP's preventive arm, the EB continues to rely on much the same unobservable variables that have led to the criticism of the structural balance. ${ }^{20}$ Moreover, it also includes additional adjustments that cause a deviation from the SB and whose data source is not readily available.

\section{Structural Balance and the MTO}

For the operation of the EB, to determine the convergence margin it is necessary to know whether a given country has already reached the respective MTO or not, which is defined in structural terms. Therefore, the working of the EB is still reliant on the structural balance calculation and not a substitute for it. It is, however, possible to devise an expenditure rule that does not require a link to the MTO, substituting it with the debt ratio: the expenditure aggregate should grow by less than the reference rate for the GDP for countries who are above the debt reference value.

\section{Potential GDP}

The potential GDP necessary to find the medium-term reference rate for the EB is an unobservable variable derived from the Commonly Agreed Methodology, which is at the center of the criticism for the calculation of the structural balance. Such methodology is based on a production function (Havik et al. 2014) and subject to successive refinements discussed in the Output Gaps Working Group of the EU

\footnotetext{
19 The cyclical component of the expenditure is obtained multiplying the output gap by the semi-elasticity of the expenditure to the cycle. Only unemployment-related expenditures are assumed to react to the economic cycle (Mourre et al. 2013; Mourre et al. 2014).

${ }^{20}$ It must be recognized that there are indeed few truly observed macroeconomic aggregates, even the GDP statistic relies on some extrapolation. However, there is a clear distinction between the measurement error of statistical variables and that of variables that can be estimated by means of different methodologies with very different outcomes—-such as the potential output.
} 
Economic and Financial Committee. Yet, there are many methodological challenges to estimate such non-observable indicator (Cotis et al. 2004; EU Independent Fiscal Institutions 2018a).

The EB requires a medium-term potential GDP growth rate to act as the reference rate for expenditure growth. It might be argued that such rate is more stable than the output gap indicator used in the yearly calculation of the structural balance, as it is a ten-year moving average of the potential output growth rates, which, in turn, are more stable than the level. ${ }^{21}$ However, the calculation is still quite sensitive to the latest forecast available because of the use of forward-looking (forecast) data inputs and to the method used to estimate the potential output. ${ }^{22}$ The (European Commission 2020b) purposes the moving average of actual GDP growth rates as a possible modelling alternative. Yet, if a given country is experiencing a declining trend in GDP growth, the use of past data could lead to a very loose expenditure constraint.

\section{Cyclical Unemployment Expenditure}

The EB indicator removes the "cyclical unemployment expenditure" as it is one of the components of expenditure that is not in the direct control of the policymaker. For this the following formula is used:

$$
\text { Cyclical UnExp } \operatorname{UnExp}_{t} * \frac{\mathrm{UR}_{t}-\mathrm{NAWRU}_{t}}{\mathrm{UR}_{t}},
$$

where the cyclical unemployment compensation expenditure is a function of the total unemployment compensation expenditure (UnExp) and of the excess in the unemployment rate (UR) vis-à-vis the non-accelerating wage rate of unemployment (NAWRU), another unobservable variable that enters the toolkit for the estimation of the structural balance. ${ }^{23}$ Consequently, when the unemployment rate is above the NAWRU part of the unemployment compensation expenditure is subtracted from the expenditure aggregate subject to the EB.

However, this formulation does not ensure consistency with the structural balance calculation. To calculate the structural balance, it is necessary to remove the cyclical component of the budget balance using the Commonly Agreed Methodology. This is a two-step approach that requires the estimation of the output gap in the first step and then the multiplication of such output gap by the semi-elasticities of government revenue and expenditure to output in the second step. As such semi-elasticity

\footnotetext{
21 To enhance the predictability of the ex-post assessment's outcome, the medium-term potential GDP growth rate applied to set the requirements for year $t$ is calculated based on the Commission Spring forecast in $t-1$ and kept "frozen" until the assessment of compliance in May of year $t+1$.

22 (Darvas et al. 2018) found evidence of pro-cyclical revisions in the estimates of potential output and recommended excluding forecasted figures from medium-term potential growth calculations beyond the forecast made for the current year.

23 The estimation of the NAWRU is problematic in real time and prone to pro-cyclicality at the sample end, especially in the neighbourhood of turning points that recent methodological changes have tried to minimize (see Planas et al. 2017).
} 
is negative for all Member States, when the output gap is negative the cyclical component of expenditure is positive: during bad economic times the expenditure-toGDP ratio increases reflecting the work of the automatic stabilizers-the increase in unemployment compensation expenditure leaving unchanged the other expenditure. In the case of the EB framework, the cyclical unemployment expenditure is positive when the unemployment rate exceeds the NAWRU.

There would be consistency with the structural balance pillar if whenever the output gap is negative, the unemployment rate also surpasses the NAWRU, i.e., when they show opposite signs. However, this is not always the case as the NAWRU is just one element of the production function used to derive the potential output (and ultimately the output gap). As a matter of fact, using the Spring 2020 Commission forecast between 2000 and 2019 for the 27 Member States and the UK there is a divergence between the sign of the cyclical component of government expenditure and the sign of the cyclical unemployment expenditure in $1 / 4$ of the observations (143 cases in 559 combinations). For instance, during the last upswing, for Germany in 2016 and 2017, the output gap was reported as positive, leading to a negative cyclical component of expenditure, while the EB cyclical unemployment was positive.

The differences are not very large and eventually compensate each other over time. However, the introduction of such an unobservable component hinders the operationalization of the benchmark without even ensuring consistency with the SBB. Since the purpose of the EB is to ultimately reach a reference growth rate rather than a reference level for the expenditure, it is difficult to understand the need to explicitly model the cyclical unemployment expenditure, since the unemployment expenditure is a small part of total expenditure. Yet, this would remove any adjustment for the economic cycle. Alternatively, it would be much simpler to just remove all unemployment compensation expenditure or a deviation from a simple moving average. There would be simplicity gains without much loss of cyclical adjustment properties, as, in practice, the NAWRU follows narrowly the observed unemployment rate.

\section{Discretionary Revenue Measures (DRM)}

Whenever a government is willing to raise taxes to finance a spending increase, it does not add, ceteris paribus, to debt sustainability concerns. Consequently, as the EB focuses only on the expenditure side of the budget, it is necessary to allow for increases in expenditure explicitly financed by discretionary tax increases. Otherwise, it would be impossible to increase the expenditure-to-GDP ratio when complying with the EB. However, in practice, there are several data availability and measurement issues regarding discretionary revenue measures, as is recognized by the (European Commission 2020b). These issues are aggravated for IFIs that are outside of the official circle comprising the national authorities and the Commission.

In practice, Euro-area Member States are compelled to include in the Draft Budget Plan (DBP) for year $t$ (submitted by 15 of October $t-1$ ) a table stating the total DRM and the amounts to be excluded from the EB, providing aggregate figures expressed in percentage of GDP. Another table provides a list of the planned 
DRM. The Commission makes a judgment about it, which is not public, and later, in November $t-1$, publishes in the Autumn Forecast (AF) an aggregate figure for the DRM on current revenue and capital transfers received. The assessment of compliance with the EB is made in the Spring of $t+1$, using the Spring Forecast (SF) data. However, in this forecast there is no breakdown of the final SF data on DRM (apart from the distinction between total current and capital revenue) and there is a complete lack of transparency regarding how the final figures are obtained since there isn't any known published source for the data.

To check the stability of this crucial variable, Table 1 shows different figures published over time for a selection of countries with an amount of DRM of at least $0.5 \%$ of GDP (in absolute terms) in 2019: the amount identified by the national authorities in the DBPs submitted in October 2018; the first assessment by the Commission in the AF/2018; and the final figures for 2019 from the SF/2020, on which the assessment of compliance is based. When comparing the initial DBP reporting with the assessment data, there is a large difference in the case of Cyprus, France, Latvia, and Luxemburg. In absolute terms, such difference is equal or larger than the "threshold of significance" for a significant deviation (0.5\% of GDP in a single year or cumulatively in two consecutive years), which means that the size of DRM might be sufficient by itself to make a difference between compliance and a significant deviation from the requirements of the preventive arm of the SGP. It is also noteworthy that for the case of Latvia and Luxembourg there is a change in the sign of the DRM: while the authorities reported tax increases in their DBP, in the end, tax cuts were applied.

\section{Other Particularities}

The EB excludes the expenditure financed by the EU funds since such expenditure is neutral for the budget balance. It is, however, hard to obtain accurate information in real-time on such flows of financing. Given the operational complexity of structural funds, it is difficult to forecast the transfer of funds from the EU budget.

Regarding public investment, the EB considers a moving average of four years for the nationally financed investment instead of the actual investment in year $t$. According to the European Commission (2020b), this smoothing of public investment is "to protect the sustainable part of public investment" or, in another formulation, "to protect the non-excessive part of public investment". ${ }^{24}$ Therefore, only when the investment in a given year is higher than in the previous three it penalizes the EB, while an investment cut is not immediately fully reflected into a lower spending aggregate. However, when a large variation in investment occurs, this treatment is a source of

\footnotetext{
${ }^{24}$ A parallel discussion that is outside the scope of this paper is the consideration of a golden rule or using net investment instead of gross investment in a spending rule (Darvas and Anderson 2020; European Fiscal Board 2020b; EU Independent Fiscal Institutions 2021). The use of net investment would require a high quality and harmonized calculation of public capital depreciation in the EU, but the progress towards the adoption an European Public Sector Accounting Standards has been slow since 2013, despite an increasing adoption of accruals accounting (European Commission 2019a). (Schreyer, 2004) gives an overview of capital services measurement issues in national accounts.
} 
inconsistency with the other rules applying to the budget balance, to the structural budget balance, and to the debt that only consider the actual investment (and its respective financing needs) in year $t$.

\section{The IFIs' Role in the EB}

The 2012 Fiscal Compact of the TSCG calls for independent fiscal institutions at the national level to monitor compliance with the rules there set in paragraph 1 of Article $3 .^{25}$ Namely, it prescribes that "Progress towards, and respect of, the mediumterm objective shall be evaluated on the basis of an overall assessment with the structural balance as a reference, including an analysis of expenditure net of discretionary revenue measures, in line with the revised Stability and Growth Pact". Whenever significant observed deviation from the MTO or the adjustment path towards it is observed, a correction mechanism shall be triggered automatically at the national level. The respective national IFI is involved in such correction mechanism at the national level.

Due to the Fiscal Compact many Euro-area countries have also transposed into their national legislation the EB. Since the national IFI must monitor the compliance with the numerical rules set at the national level, in such cases it must assess compliance with the EB. However, the creation of the EB in 2011 preceded the consideration (in 2013) of national IFIs in the EU fiscal framework and no amendment was made to the rules governance: as argued before, the EB calculation is defined by the European Commission and must use Commission's data for year $t$ from the Spring Forecast made in year $t+1$ on NAWRU, DRM, and EU funds; while the Spring forecast made in year $t-1$ estimates are used as data source for the "frozen" components, i.e. for the convergence margin and for the potential output.

Given the aforementioned discretion in the estimate for DRMs by the Commission and the lack of transparency in the process, together with the usual revisions in the output gap components (NAWRU) used for year $t$ (from the Autumn Forecast in November of year $t$ to the Spring Forecast in May of year $t+1$ ), and the difficulty in obtaining real-time accurate data on EU funds, it is very challenging for a national IFI to assess compliance with the requirements on the expenditure net of DRM, set in national legislation and in the TSCG, before the Commission assessment in May $t+1$. Yet, if the assessment of the national IFI is to be meaningful, it must be made before or at the same time as the Commission. Doing it afterward, or even after the ECOFIN Council assessment and just reproduce the international assessment, does not add value to the process nor to the national appropriation of fiscal rules. Diverging ex-post from such assessment does not seem to be possible since several steps in the calculation of the EB foreseen in the SGP are based on the mentioned Commission's data and definition. Yet, when the assessment is made before the Commission, given that the threshold for a significant deviation is just a deviation of 0.5 p.p. of GDP there is a considerable risk of reaching a different conclusion just on the

${ }^{25}$ The same role for IFIs is given also by the 2013 Two-Pack Regulation (EU) No 473/2013.

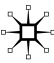


Table 1 Selected DRM for the year 2019 (\% of GDP)

\begin{tabular}{lcccl}
\hline & $\mathrm{DBP} / 2019$ & $\mathrm{AF} / 2018$ & $\mathrm{SF} / 2020$ & $\begin{array}{l}\text { Difference } \\
\text { SF/2020- } \\
\end{array}$ \\
& $2018 / 10$ & $2018 / 11$ & $2020 / 05$ & $\mathrm{DBP} / 2019$ \\
\hline Belgium & -0.2 & -0.3 & -0.7 & -0.5 \\
Cyprus & 0.4 & 0.4 & 1.5 & 1.1 \\
France & -0.2 & -0.9 & -1.1 & -0.9 \\
Latvia & 0.2 & -0.5 & -0.5 & -0.7 \\
Luxembourg & 0.3 & -0.3 & -0.4 & -0.7 \\
Netherlands & 0.4 & 0.5 & 0.4 & 0.0 \\
\hline
\end{tabular}

Source of data: national DBP for 2019, submitted by October 15, 2018; European Commission's Autumn forecast 2018 (AF/2018), and Spring Forecast 2020 (SF/2020), codes 1.0.319.0.UDMGCR "discretionary measures current revenue: general government" plus 1.0.319.0.UDMGKTR "discretionary measures capital transfers received: general government".

account of outdated data, which is difficult to explain, and consequently potentially costly for the reputation of the IFI. While one of the major advantages of IFIs is to offer an independent assessment, the outdated data on DRM is of particular concern as IFIs do not receive beforehand the final data on which the Commission will base its judgment since they are not involved in the final classification. This hardly can be overcome with own estimates as most EU IFIs have no role on policy costing. ${ }^{26}$

Naturally, when there is a divergence between the structural balance evolution and the EB analysis, the national IFI can reach a different conclusion from the Commission or the ECOFIN on whether or not a significant deviation exists and publicly communicate that to the public. It involves a communication challenge, and its practical impact regarding triggering the automatic correction mechanism depends on national legislation provisions.

In short, to be of use for IFIs, the calculation of the expenditure benchmark should be simplified and made more transparent. ${ }^{27}$ If the unobservable elements such as DRM and NAWRU are to be kept in the calculation (and not previously "frozen") it would be necessary to involve the respective IFI in its estimation, increasing the

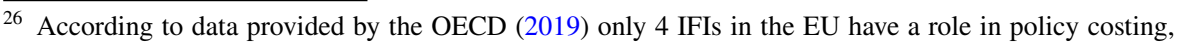
and of those only two institutions combine such a role with the role of monitoring the compliance with fiscal rules. Actually, the policy costing remit is much underrepresented in the EU compared with similar institutions in the rest of the OECD: only 17\% (4 out of 24) of the EU IFIs have such role, when in the rest of the OECD the proportion is $91 \%$ (10 out of 11). Moreover, it should be mentioned that policy costing is very demanding in terms of information, human and financial resources. For further information on the IFIs remits (Calmfors and Wren-Lewis, 2011) provide an early overview, while the e-book by Debrun and Beetsma (2018) and Kopits (2013) include significant contributions on the role of IFIs in different fiscal frameworks and the challenges such novel institutions face in practice.

${ }^{27}$ It should be mentioned that after the publication of the Commission's assessment, IFIs have access to the calculation of the EB on the so-called "transparency files", but without the breakdown of the DRM considered.
} 
transparency of the process. It is also essential to improve the timeliness of the data on expenditure financed by the EU budget.

\section{Conclusions and Policy Recommendations}

Several EU fiscal framework reform proposals focus on one anchor and one or some operational rules. It is the case of the proposals by the European Fiscal Board (2018, 2019), Kopits (2018), Bénassy-Quéré et al. (2018) or Darvas et al. (2018), Darvas and Anderson (2020) and others. Among the authors who believe in fiscal rules to constrain and guide discretionary fiscal policymaking, it is consensual that such rules should be as transparent and simple as possible, while at the same time being smart enough in order not to induce procyclical policies. To ensure effectiveness the rules' targets should be as far as possible under the control of the Government.

Common to many of such reform proposals is the preference for a net expenditure growth as the operational rule (with some nuances). ${ }^{28}$ However, as this paper shows, the EB in its present form is not the "silver bullet" for the simplification of the EU fiscal framework. Although the structural balance rule was heavily criticized for relying too much on non-observable variables, the EB cannot be a replacement for that rule as in its calculation it is necessary to determine if the Member State's structural balance is at its respective MTO to further calculate and apply the calibrated convergence margin that defines if the net expenditure modified aggregate can increase at a pace in line or below the medium-term potential output growth. Due to the non-observable components necessary to its calculation, the EB does not qualify as an operational rule under the direct control of the Government. To start with, the budget process in EU countries is not based on the ESA2010 national accounts definition of expenditure, as many countries still follow cash accounting. This makes it difficult to monitor possible deviations from planned expenditure during the year. Furthermore, revisions in the non-observable components of the EB could by themselves lead to unforeseen deviations, including in the final figures on DRM.

The 2011 EB did not consider the existence of IFIs operating at the national level, which were added to the European fiscal framework just in 2013. As a result, the methodology used to calculate the EB is completely reliant on data and the judgement from the European Commission based on national authorities reporting. IFIs have no privileged access to such data before publication, and the process is not sufficiently transparent. Therefore, for the EB to become an operational rule, and for the national IFIs to have a significant role in monitoring compliance as required by the legislation and the TSCG, its calculation should be much simplified, made more transparent, and formally involving the IFIs in the calculation of several inputs required. It is also urgent to improve the data reporting to enable a real-time

\footnotetext{
${ }^{28}$ Back in 2016, Bruegel's contribution to the reform of the EU fiscal framework by (Claeys et al. 2016) already advocated several corrections to the EB to become a public expenditure rule with debt-correction feedback.
} 
knowledge of the flows of EU funds, which are also essential to the calculation, and will likely increase as a response to the current crisis. All these governance enhancements would improve compliance and enforceability.

Therefore, this contribution argues in favour of an increase in transparency, the involvement of national IFIs in the calculation of unobservable variables (including the DRM), and the simplification of this benchmark. The precise way to simplify this indicator will depend on the options adopted in the overall reform of the EU fiscal rules, namely in what regards the role of the structural balance rule. If the structural balance rule is to be retained, then one possibility would be to minimize the inconsistencies between the two indicators redefining some building blocks of the EB or of the SBB, such as the treatment of investment, the relevant potential GDP, and the cyclical adjustment. If, on the contrary, the structural balance rule is to be abandoned, then the EB could also get rid of the unobservable variables, potential GDP and NAWRU. Another possibility is a mix of the two options, keeping the SBB and base the EB just on observable variables, further decoupling the two indicators, however at the cost of increasing the opportunities for Governments to "pick-and-choose" the preferred indicator.

The existence of effective national IFIs allows also for a more radical reform letting the operational rules be defined at the national level, anchored in proper Medium-Term Budget Frameworks (MTBF), and just retain higher level rule(s) at the supranational level, e.g. a reformed debt rule.

\section{Appendix: Conciliation Between the SBB and the EB}

Based on European Commission (2011, p. 69; Irish Fiscal Advisory Council (2015), one way to show the link between the EB and the SBB is to consider the total differential of the structural deficit (SDEF) to potential GDP $(Y)$ ratio:

$$
d\left(\frac{\mathrm{SDEF}}{Y}\right)=\frac{d(\mathrm{SDEF})}{Y}-\frac{\mathrm{SDEF}}{Y} g
$$

where $g$ is the potential GDP growth rate. Since the structural deficit is, by definition, equal to total structural expenditure less structural revenue $(R)$, and the total structural expenditure could be divided into structural primary expenditure (PE) and interest payments $(r B)$, where $r$ is the implicit rate on debt $(B)$, then:

$$
\mathrm{SDEF}=\mathrm{PE}+r B-R .
$$

Using (5), we can rewrite (4) as:

$$
\mathrm{d}\left(\frac{\mathrm{SDEF}}{Y}\right)=\frac{d(\mathrm{PE})}{Y}-\frac{\mathrm{PE}}{Y} g+\frac{d(r B)}{Y}-\frac{r B}{Y} g-\frac{d R}{Y}+\frac{R}{Y} g .
$$

Taking into account that: 


$$
d\left(\frac{R}{Y}\right)=\frac{d(R)}{Y}-\frac{R}{Y} g
$$

and

$$
d\left(\frac{r B}{Y}\right)=\frac{d(r B)}{Y}-\frac{r B}{Y} g
$$

the previous expression (6) can be rewritten as:

$$
d\left(\frac{\mathrm{SDEF}}{Y}\right)=\frac{d(\mathrm{PE})}{Y}-\frac{\mathrm{PE}}{Y} g+d\left(\frac{r B}{Y}\right)-d\left(\frac{R}{Y}\right),
$$

which when solved for $d(\mathrm{PE}) / Y$ and dividing both terms by $\mathrm{PE} / Y$ yields:

$$
\frac{d(\mathrm{PE})}{\mathrm{PE}}=g+\frac{d(\mathrm{SDEF} / Y)}{\mathrm{PE} / Y}+\frac{d(R / Y)-d(r B / Y)}{\mathrm{PE} / Y}
$$

Now it is possible to compare this expression with the formula used by the EB which requires that the modified (primary) expenditure aggregate net of one-offs and DRM $\left(m g_{t}\right)$ growths at a pace in line with the reference medium-term potential growth $(\bar{g})$ less the convergence margin. The convergence margin is given by the required annual adjustment in the structural balance expressed in percentage points of GDP (adjustment $t_{t}$ ) divided by the observed primary balance ( $\mathrm{PE}^{\mathrm{obs}}$ ) to GDP ratio in the previous year, yielding:

$$
m g_{t}=\bar{g}-\frac{\text { adjustment }_{t}}{\mathrm{PE}_{t-1}^{\mathrm{obs}} / \mathrm{GDP}_{t-1}}
$$

When the Member State concerned is not yet at the respective MTO, the SBB should show, as a general rule, an annual improvement by at least $0.5 \%$ of potential GDP. In practice, this requirement is conditional on the state of the economy, calling for a larger improvement when in "good times" and high debt, and a smaller improvement or even no improvement at all when in "bad times". The precise figure on the required adjustment, i.e. the required annual improvement in the structural balance $\left(\mathrm{SDEF}_{t}^{\mathrm{req}}\right)$ is given by a matrix of requirements, published in the SGP Code of Conduct, which takes into account the debt level and the economic cycle:

$$
\text { adjustment }_{t}=-d\left(\mathrm{SDEF}_{t}^{\mathrm{req}} / Y_{t}\right)
$$

which means that we could rewrite the EB requirement (11) as:

$$
m g_{t}=\bar{g}-\frac{-d\left(\mathrm{SDEF}_{t}^{\mathrm{req}} / Y_{t}\right)}{\mathrm{PE}_{t-1}^{\mathrm{obs}} / \mathrm{GDP}_{t-1}}
$$

Expression (13) can then be compared with (10) to show the link between the two indicators. 
Acknowledgments The opinions here expressed are solely of the author, and not those of the Portuguese Public Finance Council. The author would like to thank Ariana Paulo, George Kopits, Jorge Garrido, Miguel St Aubyn, Nazaré da Costa Cabral, Nuno Gonçalves and Paul de Grauwe for useful technical exchanges and comments. The text benefited also from very useful insights and suggestions from two anonymous reviewers to whom the author is highly indebted. The author, however, bears full responsibility for the text.

\section{References}

Andrle, M. et al. (2015) Reforming Fiscal Governance in the European Union. SDN/15/09. Available at: https://www.imf.org/external/pubs/ft/sdn/2015/sdn1509.pdf.

Barbier-Gauchard, A., Baret, K. and Minea, A. (2021) National Fiscal Rules and Fiscal Discipline in the European Union. Applied Economics (hal-02992219f; forthcoming). Available at: https://hal. uca.fr/hal-02992219.

Baret, K. and Barbier-Gauchard, A. T. P. (2021) Forecasting the Stability and Growth Pact compliance using Machine Learning. Strasbourg. Available at: https://econpapers.repec.org/RePEc:ulp: sbbeta:2021-01.

Bedogni, J. and Meaney, K. (2017) EU Fiscal Rules and International Expenditure Rules. Staff Paper 2017.

Beetsma, R., Debrun, X. and Sloof, R. (2017) Working paper series. ECB Working Paper Series (2091). doi: https://doi.org/10.1111/j.1467-629X.1980.tb00220.x.

Bénassy-Quéré, A. et al. (2018) Reconciling risk sharing with market discipline: a constructive approach to euro area reform. CEPR Policy Insight, (91). Available at: https://cepr.org/sites/ default/files/policy_insights/PolicyInsight91.pdf.

Bergman, U.M., and M. Hutchison. 2015. Economic stabilization in the post-crisis world: Are fiscal rules the answer? Journal of International Money and Finance 52: 82-101. https://doi.org/10. 1016/j.jimonfin.2014.11.014.

Blanchard, O., A. Leandro, and J. Zettelmeyer. 2021. Redesigning EU fiscal rules: From rules to standards. Economic Policy. https://doi.org/10.1093/epolic/eiab003.

Blanchard, O., Leandro, Á. and Zettelmeyer, J. (2020) Revisiting the EU fiscal framework in an era of low interest rates. mimeo - European Commission. Available at: https://ec.europa.eu/info/sites/ info/files/s3-p_blanchard_et_al_0.pdf.

Calmfors, L., and S. Wren-Lewis. 2011. What should fiscal councils do? Economic Policy 26(68): 649-695. https://doi.org/10.1111/j.1468-0327.2011.00273.x.

Cangiano, M., T. Curristine, and M. Lazare. 2013. Public financial management and its emerging architecture. Washington, D.C.: International Monetary Fund. https://doi.org/10.5089/97814 75531091.071.

Carnot, N. (2014) Evaluating Fiscal Policy: a rule of thumb. 526. Brussels: European Commission. Available at: https://ec.europa.eu/economy_finance/publications/economic_paper/2014/pdf/ ecp526_en.pdf.

Claeys, G., Darvas, Z. and Leandro, Á. (2016) A proposal to revive the European Fiscal Framework. Bruegel Policy Contribution, (07), pp. 1-20. Available at: https://www.bruegel.org/2016/03/aproposal-to-revive-the-european-fiscal-framework/.

Constâncio, V. 2020. The return of Fiscal Policy and the Euro area fiscal rule. Comparative Economic Studies 62(3): 358-372. https://doi.org/10.1057/s41294-020-00122-3.

Cordes, T. et al. (2015) Expenditure rules: Effective tools for sound fiscal policy?

Cotis, J.-P., Elmeskov, J. and Mourougane, A. (2004) Estimates of potential output: benefits and pitfalls from a policy perspective. In The Euro Area Business Cycle: stylized facts and measurement issues, ed. Reichlin, L. CEPR.

Cottarelli, C., and M. Guerguil. 2015. Designing a European Fiscal Union. London: Routledge.

Darvas, Z. and Anderson, J. (2020) New life for an old framework: redesigning the European Union's expenditure and golden fiscal rules. Available at: https://www.bruegel.org/wp-content/uploads/ 2020/10/IPOL_STU2020645733_EN.pdf. 
Darvas, Z., Martin, P. and Ragot, X. (2018) European fiscal rules require a major overhaul. Policy Contribution, 18(October), pp. 1-18. Available at: https://www.bruegel.org/wp-content/uploads/ 2018/10/PC-18_2018.pdf.

Debrun, X. et al. (2008) Tied to the mast? National fiscal rules in the European Union. Economic Policy, pp. 297-362. doi: https://doi.org/10.1111/j.1468-0327.2008.00199.x.

Debrun, X. and Beetsma, R. (2018) Independent Fiscal Councils: Watchdogs or lapdogs? VoxEU. org. Edited by X. Debrun and R. Beetsma. CEPR Press. Available at: https://voxeu.org/system/ files/epublication/Fiscal_Councils.pdf.

Debrun, X., and L. Jonung. 2019. Under threat: Rules-based fiscal policy and how to preserve it. European Journal of Political Economy 57: 142-157. https://doi.org/10.1016/j.ejpoleco.2018.09. 001.

Deroose, S. et al. (2018) EU fiscal rules: Root causes of its complexity. VOX CEPR Policy Portal. Available at: https://voxeu.org/article/eu-fiscal-rules-root-causes-its-complexity.

EU Independent Fiscal Institutions (2018a) A Practitioner 's Guide to Potential Output and the Output Gap, EU Independent Fiscal Institutions. Available at: https://www.euifis.eu/eng/fiscal/228/a-pract itioners-guide-to-potential-output-and-the-output-gap.

EU Independent Fiscal Institutions (2018b) Medium-Term Budgetary Frameworks. Available at: https:// www.euifis.eu/images/MTBF_PAPER.pdf.

EU Independent Fiscal Institutions (2021) The public debt outlook in the EMU post Covid: A key challenge for the EU fiscal framework. Available at: https://www.euifis.eu/images/Network of EU IFIs - The public debt outlook post Covid - A key challenge for the EUFF(2).pdf.

European Commission (2011) 2011 Report on Public Finances in EMU. European Economy, 3(September). Available at: https://ec.europa.eu/economy_finance/publications/european_economy/2011/ ee3_en.htm.

European Commission (2019a) Reporting on the Progress as Regards the European Public Sector Accounting Standards (EPSAS). SWD(2019) 204 final. Brussels.

European Commission (2019b) Vade Mecum on the Stability \& Growth Pact. European Economy Institutional Paper, (101). doi: https://doi.org/10.2765/724849.

European Commission. 2020a. Communication on Economic Governance Review Report on the application of Regulations (EU) No 1173/2011, 1174/2011, 1175/2011, 1176/2011, 1177/2011, 472/2013 and 473/2013 and on the suitability of Council Directive 2011/85/EU. Brussels. Available at: https://ec.europa.eu/info/business-economy-euro/economic-and-fiscal-policy-coordination/eu-econo mic-governance-monitoring-prevention-correction/economic-governance-review_en.

European Commission. 2020b. Performance of spending rules at EU and national level-a quantitative assessment Public finances in EMU, Report on Public Finances in EMU 2019133 https://doi.org/ $10.2765 / 92125$

European Commission. 2021. Communication from the Commission to the Council - One year since the outbreak of COVID-19: fiscal policy response. Brussels. Available at: https://ec.europa.eu/info/files/ one-year-outbreak-covid-19-fiscal-policy-response_en.

European Fiscal Board. 2018. Annual Report 2018. Available at: https://ec.europa.eu/info/publications/ 2018-annual-report-european-fiscal-board_pt.

European Fiscal Board. 2019. Annual Report 2019. Available at: https:/ec.europa.eu/info/publications/ 2019-annual-report-european-fiscal-board_en.

European Fiscal Board. 2020a. Annual Report 2020. Brussels. Available at: https://ec.europa.eu/info/ publications/2020-annual-report-european-fiscal-board_en.

European Fiscal Board. 2020b. Assessment of the fiscal stance appropriate for the euro area in 2021, (July 2020). Available at: https://ec.europa.eu/info/sites/info/files/2020_06_25_efb_assessment_of_ euro_area_fiscal_stance_en.pdf.

Gaspar, V. 2020. Future of Fiscal Rules in the Euro Area. Keuynote speech at Workshop on "Fiscal Rules in Europe: Design and Enforcement” organised by DG ECFIN. Brussels. Available at: https://www. imf.org/en/News/Articles/2020/01/28/sp012820-vitor-gaspar-fiscal-rules-in-europe.

Guerguil, M., P. Mandon, and R. Tapsoba. 2017. Flexible fiscal rules and countercyclical fiscal policy. Journal of Macroeconomics 52: 189-220. https://doi.org/10.1016/j.jmacro.2017.04.007.

Hauptmeier, S. and Kamps, C. 2020. Debt rule design in theory and practice: the SGP's debt benchmark revisited. 2379. Available at: https://ideas.repec.org/p/ecb/ecbwps/20202379.html.

Havik, K. et al. 2014. The Production Function Methodology for Calculating Potential Growth Rates \& Output Gaps. European Economy Economic Papers, 535(November). doi: https://doi.org/10.2765/ 71437. 
IMF. 2014. Public Expenditure Reform: Making Difficult Choices. Fiscal Monitor (April), pp. 21-56. Available at: https://www.imf.org/en/Publications/FM/Issues/2016/12/31/Public-ExpenditureReform-Making-Difficult-Choices-41121.

Irish Fiscal Advisory Council (2015) The EU Expenditure Benchmark: Operational Issues for Ireland in 2016. Available at: https://www.fiscalcouncil.ie/wp-content/uploads/2012/01/ExpenditureBenc hmarkNote_310315_Final_1.5.pdf.

Kopits, G. 2013. Restoring public debt sustainability the role of independent fiscal institutions. Edited by G. Kopits. doi: https://doi.org/10.1093/acprof:oso/9780199644476.001.0001.

Kopits, G. 2018. How could the Stability and Growth Pact be simplified? Brussels. Available at: https:// www.europarl.europa.eu/RegData/etudes/IDAN/2018/614509/IPOL_IDA(2018)614509_EN.pdf.

Kopits, G. and Symansky, S. A. 1998. Fiscal policy rules. 162. IMF. Available at: http://www.imf.org/ external/pubs/cat/longres.aspx?sk=2608.0 (Accessed: 8 January 2011).

Larch, M., E. Orseau, and W. van der Wielen. 2021. Do EU fiscal rules support or hinder counter-cyclical fiscal policy? Journal of International Money and Finance 112: 102328. https://doi.org/10.1016/j. jimonfin.2020.102328.

Lledó, V. et al. 2017. Fiscal Rules at a Glance. International Monetary Fund, (March), pp. 1-70. Available at: http://www.imf.org/external/datamapper/fiscalrules/Fiscal Rules at a Glance - Background Paper.pdf.

Marinheiro, C. 2008. The stability and growth pact, fiscal policy institutions and stabilization in Europe. International Economics and Economic Policy 5(1): 189-207. https://doi.org/10.1007/ s10368-008-0110-3.

Mourre, G., et al. 2013. The cyclically-adjusted budget balance used in the EU fiscal framework: an update. Economic Papers 478: 48. https://doi.org/10.2765/3922.

Mourre, G., C. Astarita, and S. Princen. 2014. Adjusting the budget balance for the business cycle: the EU methodology. European Economy Economic papers 536: 1-40. https://doi.org/10.2765/71756.

OECD. 2019. OECD Independent Fiscal Institutions Database. OECD. Available at: http://www.oecd. $\mathrm{org} / \mathrm{gov} /$ budgeting/OECD-Independent-Fiscal-Institutions-Database.xlsx.

Planas, C., et al. 2017. NAWRU estimation using structural labour market indicators. European Economy Discussion Paper. https://doi.org/10.2765/317589.

Sacchi, A., and S. Salotti. 2015. The impact of national fiscal rules on the stabilisation function of fiscal policy. European Journal of Political Economy 37: 1-20. https://doi.org/10.1016/j.ejpoleco.2014. 10.003 .

Schreyer, P. 2004. Capital stocks, capital services and multi-factor productivity measures. OECD Economic Studies 2: 163-184. https://doi.org/10.1787/eco_studies-v2003-art11-en.

Strauch, R., M. Hallerberg, and J. von Hagen. 2009. 'How forms of fiscal governance affect fiscal performance. Cambridge: Cambridge University Press.

Tapsoba, R. 2012. Do National Numerical Fiscal Rules really shape fiscal behaviours in developing countries? A treatment effect evaluation. Economic Modelling 29(4): 1356-1369. https://doi.org/10. 1016/j.econmod.2012.03.003.

Thygesen, N. et al. 2020. Reforming the EU fiscal framework: Now is the time, VoxEU.org. Available at: https://voxeu.org/article/reforming-eu-fiscal-framework-now-time. (Accessed: 16 November 2020).

Thygesen, N. et al. 2021. High debt, low rates, and tail events: rules-based fiscal frameworks under stress, VoxEU.org. Available at: https://voxeu.org/article/rules-based-fiscal-frameworks-under-stress (Accessed: 8 March 2021).

Wyplosz, C. 2013. Fiscal Rules Theoretical Issues and Historical Experiences. In Fiscal Policy after the Financial Crisis by editors Alesina, A. and Giavazzi, F. National B. University of Chicago Press, pp. 495-525. Available at: https://www.nber.org/system/files/chapters/c12656/c12656.pdf.

Publisher's Note Springer Nature remains neutral with regard to jurisdictional claims in published maps and institutional affiliations. 